\title{
Struktur Vegetasi Kawasan Hutan Pada Zona Ketinggian Berbeda di Kawasan Gunung Galunggung Kabupaten Tasikmalaya Jawa Barat
}

\author{
Suryana, Johan Iskandar, Parikesit, Ruhyat Partasasmita, dan Budi Irawan
}

Departemen Biologi, Fakultas Matematika dan Ilmu Pengetahuan Alam, Universitas Padjadjaran, Jl. Raya BandungSumedang km. 21 Jatinangor 45363, Telp/fax: 0227796412, Email: suryana.bio@unpad.ac.id

\begin{abstract}
ABSTRAK
Vegetasi Hutan di Kawasan Hutan Gunung Galunggung Kabupaten Tasikmalaya Jawa Barat telah dilakukan pada Maret - November 2016. Metode yang digunakan adalah metode survey. Pengumpulan data dilakukan dengan teknik plot kuadrat yang diletakan di sepanjang transek. Sebanyak 43 jenis tumbuhan telah ditemukan yang terbagi ke dalam kategori pohon dewasa, tiang, pancang, dan semai. Kategori pohon, tiang pancang dan semai berturut-turut ditemukan sebanyak sebanyak 12, 25, 23, dan 21 jenis. Kurai (Trema orientalis) adalah jenis yang menguasai pada kategori pohon, paku bagedor (Cyathea contaminans) pada kategori tiang, kiseureuh (Piper aduncum) pada kategori pancang, dan nangsi (Villebrunea rubescens) pada tingkat semai. Komposisi jenis vegetasi pada dua zona berbeda, tetapi jenisjenis tumbuhan yang dominan pada dua zona tersebut hampir sama. Hutan Gunung Galunggung masih berada dalam kondisi yang belum klimaks, populasi dan strukturnya masih dalam tahap perkembangan/tahap sekunder. Hal ini ditandai dengan tingkat keanekaragamannya yang sedang dan ditemukannya jenis huru (Litsea sp.), puspa (Schima walichii), hamerang (Vernonia arborea), dan nangsi (Villebrunea rubescens), serta jenis lainnya yang merupakan karakteristik hutan hujan pegunungan yang berada pada tahap suksesi "seral".
\end{abstract}

Kata kunci: Vegetasi, Hutan hujan pegunungan, suksesi seral

\begin{abstract}
The study of forest vegetation in the area of Galunggung Mountains, Tasikmalaya Regency, West Java have been carried out in March to November 2016. The method used is survey method. The data was collected teknic square plots placed along the transect. The research found as many as 43 in the plant species, which are divided into categories of tree, poles, saplings and seedlings. Kurai (Trema orientalis) is dominant species into tree categories, Paku bagedor (Cyathea contaminans) into poles, Kiseureuh (Piper aduncum) into saplings, and Nangsi (Villebrunea rubescens) into seedlings. The composition of vegetation types found in two different zones indicates a difference, but it can be said that the plant species are dominant in the two zones are almost the same. Galunggung forests are still in a state that has not climax, and the population structure is still in development (secondary stage). Marked with the current level of diversity and the discovery of Huru (Litsea sp.), Puspa (Schima walichii), Hamerang (Vernonia arborea), and Nangsi (Villebrunea rubescens), as well as other types that are characteristic of rain forest at mountian seral successional stage.
\end{abstract}

Keywords: Vegetation, Rain Forest at Mountain, Seral Successional Stage

Sitasi: Suryana, Iskandar, J., Parikesit, Partasasmita, R. dan Irawan, B. (2018). Struktur Vegetasi Kawasan Hutan pada Zona Ketinggian Berbeda di Kawasan Gunung Galunggung Kabupaten Tasikmalaya Jawa Barat. Jurnal Ilmu Lingkungan, 16(2), 130-135, doi:10.14710/jil.16.2.130-135

\section{Pendahuluan}

Sumber daya lahan dan hutan merupakan kekayaan alam yang sangat besar kontribusinya bagi pembangunan Indonesia. Pemanfaatan yang tidak disertai dengan pengelolaan yang baik akan menyebabkan sumber daya alam tersebut rusak. Saat ini, kondisi sumber daya lahan dan hutan Indonesia di tandai dengan kerusakan. Data laju kerusakan hutan periode 1985-1997 tercatat sebanyak 1,6 juta ha per tahun, sedangkan pada periode 1997-2000 meningkat menjadi 3,8 juta ha per tahun (Dephut, 2007). Menurut Daryono (2009) dan Purba dkk. (2014) laju konversi hutan di Indonesia saat ini sangat tinggi yaitu sebesar 2 - 2,8 juta hektar pertahun. Penyebabnya antara lain adalah berkembangnya industri kayu, perkebunan, pertanian menetap, perladangan berpindah, pembuatan jalan dan infra struktur lainnya, pertambangan, dan pembalakan yang tidak teratur (Purbowaseso, 2004).

Selain itu meningkatnya jumlah manusia disekitar hutan menjadi ancaman bagi kelestarian hutan. Peningkatan jumlah manusia akan berbanding lurus dengan peningkatan kebutuhan sumberdaya seperti makanan, perlindungan, peralatan, lahan dan lain sebagainya (Purwaningsih dkk., 2004). Tercatat sebanyak 10,2 juta masyarakat berada di dalam dan 
sekitar kawasan hutan (PHKA, 2007). Adanya ketergantungan masyarakat terhadap sumber daya hutan mempunyai dampak terhadap perkembangan hutan. Aktifitas yang dilakukan manusia dapat menimbulkan gangguan pada proses suksesi, tekanan, atau gangguan pada sistem (Kusumo A., dkk., 2016). Lebih jauh lagi kerusakan pada daerah hutan mempunyai efek menurunkan fungsi hidroologi hutan, menaikan laju kepunahan jenis biota, dan menaikan laju terjadinya pemanasan global (Purba dkk., 2014).

Kawasan Hutan Gunung Galunggung merupakan salah satu ekosistem yang sangat penting dalam menunjang lingkungan hidup di Kabupaten Tasikmalaya. Kawasan hutan ini merupakan tangkapan dan resapan air yang sangat berperan dalam penyimpanan air baik untuk air minum, pertanian, perkebunan, wisata, dan lain-lain. Fungsi Hutan Gunung Galunggung dalam bidang ekologi, hidroorologi, konservasi keanekaragaman hayati, dan fungsi lainnya sangat ditentukan oleh kondisi hutan saat ini terutama kondisi vegetasinya.

Luas hutan lindung Gunung Galunggung sekitar 1226 ha. Sampai tahun 1963 kawasan ini masih merupakan hutan primer, kemudian berubah seiring dengan banyaknya penebangan pohon. Kerusakan vegetasi yang lebih parah lagi, terjadi saat erupsi di kawasan ini pada tahun 1982-1983. Suatu erupsi gunung berapi yang sangat khas yang tidak pernah terjadi di tempat lain di dunia. Debu dan pasir letusan menutup vegetasi di lereng gunung, hal ini menyebabkan matinya banyak pohon. Tetapi dilain pihak tanah menjadi subur sehingga pertumbuhan vegetasi setelah itu berangsur lebih baik (Widayat, dkk., 2007).

Erupsi menyebabkan informasi kondisi vegetasi hutan dan interaksinya dengan faktor biotik serta abiotik belum pernah diketahui secara ilmiah. Maka penelitian struktur vegetasi di kawasan hutan Gunung Galunggung Kabupaten Tasikmalaya Jawa Barat sangat perlu untuk dilakukan. Penelitian dilakukan di kawasan hutan Gunung Galunggung pada dua zona ketinggian berbeda.

\section{Metode Penelitian}

Penelitian ini di lakukan pada tiga kawasan yaitu kawasan sekitar pemandian Cipanas sampai Kawah Gunung Galunggung, Kawasan Punggungan Gunung bagian utara kawah di sebut Kawasan Dinding Ari Utara, dan Kawasan Punggungan Gunung bagian selatan disebut kawasan Dinding Ari Selatan. Kawasan penelitian ini diperkirakan termasuk kawasan hutan yang terkena lava dan tertutup abu letusan Gunung Galunggung pada 1982-1983.

\subsection{Metode Pengumpulan Data Vegetasi}

Metode yang digunakan adalah metode survey, pengumpulan data dilakukan dengan teknik plot kuadrat yang diletakan di sepanjang transek (Soerianegara I., 1978; Bismark, 2011; Fachrul 2012).
Pada metode ini dibuat jalur dengan petak-petak, yang masing-masing untuk semai, pancang, tiang dan pohon. Ukuran petak $2 \times 2 \mathrm{~m}$, petak $5 \times 5 \mathrm{~m}$, petak 10 $\times 10 \mathrm{~m}$ dan petak $20 \times 20 \mathrm{~m}$ masing-masing disiapkan untuk vegetasi tingkat semai, pancang, tiang dan pohon.

Pada masing-masing petak tersebut dilakukan pengukuran tinggi, diameter setinggi dada dan identifikasi jenis semai, tiang, pancang dan pohon, kemudian dicatat pada tally sheet yang telah disiapkan. Identifikasi dilakukan dengan cara membandingkannya pada buku identifikasi jenis pohon di hutan alam. Untuk jenis semai, tiang, pancang dan pohon yang tidak dikenal pada hutan alam, dilakukan identifikasi melalui koleksi contoh herbarium (Van Steenis et.al., 1975; Tjitrosoepomo, 2007; Yulianto 2014).

\subsection{Peletakan Transek dan Plot}

Tiga buah transek diletakkan secara subjektif di lokasi penelitian. Transek I dari daerah kaki gunung sekitar pemandian Cipanas menuju kawah Gunung Galunggung sampai pada ketinggian $1.000 \mathrm{~m} \mathrm{dpl}$. Transek II dan III di letakkan di dinding Ari Gunung Galunggung bagian utara dan selatan kawah pada ketinggian di atas $1.000 \mathrm{~m} \mathrm{dpl}$. Pada masing-masing transek ini kemudian ditentukan titik-titik plot sebanyak 10 buah plot. Peletakan transek ini dilakukan dengan maksud untuk mengetahui perubahan dan perbedaan struktur vegetasi di lokasi penelitian. Di bawah ini adalah Peta Lokasi Penelitian Hutan Gunung Galunggung (Gambar 1.)

Untuk melihat adanya perbedaan struktur vegetasi di daerah ketinggian yang berbeda, maka analisis data dari petak contoh yang telah dibuat dibagi menjadi dua zona ketinggian. Zona I dengan

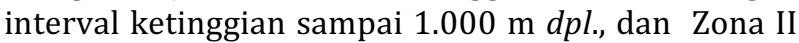
dengan interval ketinggian di atas $1.000 \mathrm{~m} \mathrm{dpl}$. Menurut Kusmana dan Istomo (1995), hutan hujan tropika terbagi menjadi tiga zona; zona I, hutan hujan bawah dengan ketinggian $2-1.000 \mathrm{~m} \mathrm{dpl.,} \mathrm{zona} \mathrm{II,}$ hutan hujan tengah dengan ketinggian 1.000-3.000 m $d p l$. dan zona III, hutan hujan atas dengan ketiggian di atas $3.000 \mathrm{~m} \mathrm{dpl}$.
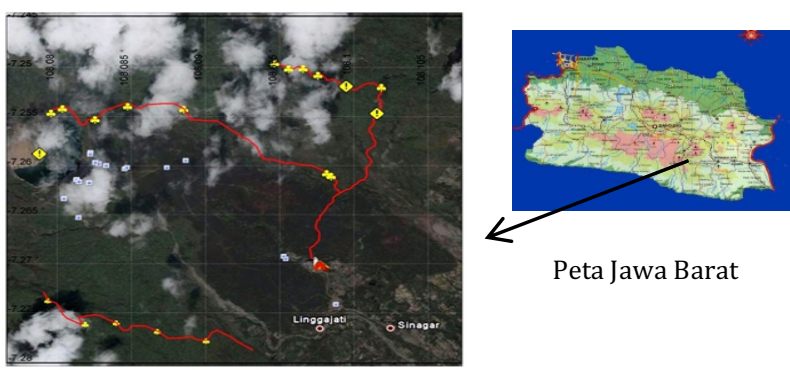

Gambar 1. Peta Lokasi Penelitian Hutan Gunung Galunggung, Kabupaten Tasiklamaya, Propinsi Jawa Barat. Transek ditandai dengan garis merah, dan tanda kuning menunjukkan plot pengambilan data. 


\subsection{Parameter yang giukur dan Analisis Data}

Untuk menentukan persentase dan besarnya pengaruh yang diberikan suatu jenis tumbuhan terhadap komunitasnya, maka dicari indeks nilai penting (Indriyanto 2006; Leksono, 2007; Fachrul 2012) menggunakan rumus sebagai berikut:

$$
\mathrm{INP}=\mathrm{FR}+\mathrm{KR}+\mathrm{DR}
$$

Kerapatan Relatif suatu spesies $(\mathrm{KR})=$

$$
\mathrm{KR}=\frac{\text { Kerapatan suatu spesies }}{\text { Kerapatan seluruh spesies }} \times 100 \%
$$

Kerapatan suatu spesies $(\mathrm{K})=$

$$
\mathrm{K}=\frac{\sum \text { ind. suatu spesies }}{\text { Luas petak contoh }}
$$

Frekuensi Relatif suatu spesies $(\mathrm{FR})=$

$$
\mathrm{FR}=\frac{\text { Frekuensi suatu spesies }}{\text { Frekuensi seluruh spesies }} \times 100 \%
$$

Frekuensi suatu spesies $(\mathrm{F})=$

$$
\mathrm{DR}=\frac{\Sigma \text { Petak contoh ditemukan suatu spesies }}{\Sigma \text { petak contoh }}
$$

Dominansi Relatif $(\mathrm{DR})=$

$$
\mathrm{DR}=\frac{\text { Dominasi suatu spesies }}{\text { Dominasi seluruh spesies }} \times 100 \%
$$

Dominansi suatu spesies $(\mathrm{D})=$

$$
\mathrm{D}=\frac{\text { Luas bidang dasar suatu spesies }}{\text { Luas petak contoh }} \times 100 \%
$$

\section{Hasil dan Pembahasan}

\subsection{Gambaran Umum Lokasi Penelitian}

Kawasan hutan Gunung Galunggung merupakan ekosistem teristrial yang sangat penting dalam menunjang lingkukangan hidup di Kabupaten Tasikmalaya. Secara geografis terletak di Kabupaten Tasikmalaya Propinsi Jawa Barat. Terdapat beberapa alternatif jalur masuk untuk menuju ke Hutan Gunung Galunggung ini, diantaranya adalah jalur masuk melalui kota Kec. Singaparna dan Kota Kec. Indihiang. Jalur masuk melalui kota Singaparna dapat ditempuh dengan jarak kurang lebih 21 km., sedangkan jalur masuk melalui kota Kec. Indihiang dapat ditempuh dengan jarak kurang lebih $17 \mathrm{~km}$.

Kondisi vegetasi umumnya sedang dalam proses suksesi vegetasi menuju ke hutan primer, kecuali kawasan sekitar pemandian Cipanas sampai kawah Gunung galunggung di mulai dari ketinggian kira-kira

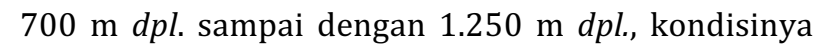
masih di dominasi oleh hutan tanaman/produksi. Beberapa contoh tumbuhan yang cukup mendominasi adalah kaliandra (Calliandra calothyrus) dan pinus (Pinus merkusii).

Kondisi kawasan dinding ari Utara dan Selatan pada umumnya sudah berupa hutan sekunder tua dengan tanda-tanda antara lain sudah ditemukan adanya jenis vegetasi hutan asli pegunungan seperti saninten (Castanopsis argentea), kurai (Trema orientalis), puspa (Schima walichii), huru (Litsea sp.), dan lain-lain. Jumlah tumbuhan pioner ke arah hutan primer seperti pohon mara (Macaranga sp.), kiseureuh (Piper aduncum) yang biasanya dominan di lahan yang sedang bersuksesi vegetasi, ternyata sudah mulai jarang ditemukan dan berangsur diganti oleh jenis pohon asli hutan primer pegunungan. Kondisi ini didukung dengan banyaknya ditemukan satwa liar dari kelas aves dan mamalia.

Selama dilakukan penelitian, di kawasan tersebut ditemukan 20 jenis burung dan enam jenis mamalia. Hal lain yang cukup menarik adalah ditemukannya jenis-jenis satwa endemik jawa dan endemik JawaBali serta di lindungi undang-undang. Jenis-jenis tersebut adalah kahkeh/cekakak (Todirhampus chloris), burung madu (Nectarinia jugularis), puyuh legeg/burung tikus (Tesia superciliaris), pecampeor/burung tepus (Stachyris melanothorax), serta Surili (Presbytis comate).

\subsection{Komposisi Jenis Vegetasi}

Berdasarkan sebaran plot kuadrat yang diletakkan secara random, di kawasan ini di temukan sebanyak 43 jenis tumbuhan, yang terbagi ke dalam kategori pohon dewasa, tiang, pancang, dan semai/tumbuhan bawah. Dari ke 43 jenis tersebut, kategori pohon ditemukan sebanyak 12 jenis, kategori tiang ditemukan sebanyak 25 jenis, kategori pancang ditemukan sebanyak 23 jenis, dan kategori semai/tumbuhan bawah ditemukan sebanyak 21 jenis. Hanya ditemukan 3 jenis dari kategori pohon yang ditemukan secara lengkap mulai dari semai hingga bentuk pohon dewasa, yaitu Beunying (Ficus fistulosa), Nangsi (Villebrunea rubescens), dan Dawola (Moutsia sp.). Ada pun yang lainnya masih terdapat variasi kategorti, hal ini menunjukkan proses suksesi masih terus berjalan.

\subsection{Struktur Vegetasi Horisontal}

Struktur vegetasi horizontal didasarkan pada pengukuran beberapa parameter, yaitu kerapatan, penyebaran, dan dominansi jenis serta indeks nilai penting yang merupakan gabungan dari dari hasil perhitungan nilai relatif dari ketiga parameter tersebut. Tabel 1. menunjukkan hasil perhitungan yang memperlihatkan jenis tumbuhan yang mendominasi kawasan dengan indeks nilai penting di atas $20 \%$. 
Tabel 1. Jenis Tumbuhan Dominan di Kawasan Hutan Gunung Galunggung pada Setiap Kategori.

\begin{tabular}{|c|c|c|c|c|c|}
\hline Nama Daerah & Nama Jenis Pohon & $\begin{array}{c}\text { KR } \\
(\%)\end{array}$ & $\begin{array}{c}\text { FR } \\
(\%)\end{array}$ & $\begin{array}{c}\text { DR } \\
(\%)\end{array}$ & $\begin{array}{l}\text { INP } \\
(\%)\end{array}$ \\
\hline Kurai & Trema orientalis & 24,44 & 25,00 & 37,02 & 86,46 \\
\hline Hamerang & Vernonia arborea & 13,33 & 11,11 & 11,90 & 36,35 \\
\hline Dadap cangkring & & 13,33 & 13,89 & 6,89 & 34,11 \\
\hline Nangsi & Villebrunea rubescens & 11,11 & 11,11 & 6.28 & 28,50 \\
\hline \multicolumn{6}{|c|}{ Tiang } \\
\hline Paku Bagedor & Cyathea contaminans & 23,77 & 13,24 & 21.39 & 58,40 \\
\hline Nangsi & Villebrunea rubescens & 7,38 & 8,82 & 10,95 & 27,15 \\
\hline Kaliandra & Calliandra calothyrus & 9,84 & 7,35 & 7,26 & 24,45 \\
\hline \multicolumn{6}{|c|}{ Pancang } \\
\hline Kiseureuh & Piper aduncum & 13,46 & 12,50 & 14,58 & 40,54 \\
\hline Kaliandra & Calliandra calothyrus & 13,46 & 6,94 & 19,54 & 39,95 \\
\hline Nangsi & Villebrunea rubescens & 10,58 & 9,72 & 9,75 & 30,05 \\
\hline \multicolumn{6}{|c|}{ Semai } \\
\hline Nangsi & Villebrunea rubescens & 9,72 & 8,64 & 10,00 & 28,36 \\
\hline Jambu Monyet & Psidium sp. & 11,11 & 4,94 & 11,43 & 27,48 \\
\hline Beunying & Ficus fistulosa & 9,72 & 7,41 & 10,00 & 27,13 \\
\hline
\end{tabular}

Keterangan: KR: Kerapatan Relatif, FR: Frekuensi Relatif, DR:Dominasi RelatifINP:Indeks Nilai Penting

Dari Tabel 1 terlihat bahwa kurai (Trema orientalis) adalah jenis pohon dewasa yang menguasai kawasan baik dari segi kerapatan, penyebaran, dan dari luas jumlah basal area. Sedangkan hamerang (Vernonia arborea) dan dadap cangkring berbeda dari kerapatan dan penyebarannya. Hamerang menguasai kawasan dengan kerapatan yang lebih tinggi di bandingkan dengan dadap cangkring, sebaliknya dadap cangkring menguasai kawasan dengan tingkat penyebaran yang lebih tinggi di bandingkan dengan Hamerang.

Vegetasi tiang umumnya mempunyai posisi vertikal di bawah vegetasi pohon dewasa, atau berada pada level kedua kanopi hutan. Berdasarkan Tabel 1, jenis paku bagedor (Cyathea contaminans) pada level kedua ini adalah jenis yang menguasai kawasan baik dari kerapatan, penyebaran, dan luas basal areanya. Jenis berikutnya adalah Nangsi (Villebrunea rubescens), menguasai kawasan dengan tingkat penyebaran yang tinggi dibandingkan dengan jenis lainnya. Dapat disimpulkan bahwa jenis ini akan menguasai kawasan di masa yang akan datang setelah vegetasi pohon dewasa sudah mati (tumbang). Paku bagedor tidak akan menguasai kawasan karena karakter jenis ini berbeda dengan nangsi. Paku bagedor adalah kelompok paku-pakuan dengan tinggi dan besar diameter batang yang terbatas.

Vegetasi pancang posisi vertikalnya di hutan berada di bawah vegetasi tiang atau berada pada level ketiga kanopi hutan. Berdasarkan Tabel 1, jenis tumbuhan yang menguasai kawasan pada level ini adalah kiseureuh (Piper aduncum) dan berikutnya adalah kaliandra (Calliandra calothyrus). Kiseureuh menguasai kawasan dengan tingkat penyebaran yang paling tinggi, sedangkan kaliandra menguasai kawasan dengan tingkat kerapatan jenis yang paling tinggi.

Vegetasi semai dijumpai di atas permukaan tanah atau pada lantai hutan. Vegetasi ini terdiri atas herba, semak, rumput, dan anakan dari vegetasi pohon. Jenis vegetasi yang paling penting pada tingkat semai di kawasan ini adalah nangsi (Villebrunea rubescens), jambu monyet (Psidium sp), dan Beunying (Ficus fistulosa). Jenis ini di masa datang akan menggantikan jenis pada level vegetasi pancang dan diduga kuat akan menguasai kawasan dibandingkan dengan jenis lain pada level vegetasi semai ini.

Beberapa jenis pohon yang ditemukan di Kawasan ini, seperti huru (Litsea sp.), puspa (Schima walichii), hamerang (Vernonia arborea), dan nangsi (Villebrunea rubescens), dan jenis lainnya merupakan cirri khas hutan hujan pegunungan yang berada pada tahap suksesi "seral" (Backer \& Bakhuizen, 1965). Jenis-jenis vegetasi seral seperti di atas menunjukkan bahwa hutan Gunung Galunggung berada dalam kondisi yang belum klimaks, populasi dan strukturnya masih dalam tahap perkembangan/tahap sekunder.

\subsection{Struktur Vegetasi Horisontal pada Dua Zona Ketinggian Berbeda}

Untuk melihat adanya perbedaan struktur vegetasi di daerah ketingian yang berbeda, maka analisis data dari petak contoh yang telah di buat di daerah penelitian di bagi menjadi dua zona ketinggian yang berbeda. Zona I dengan interval ketinggian sampai $1.000 \mathrm{~m} \mathrm{dpl}$. dan Zona II dengan interval ketinggian di atas $1.000 \mathrm{~m} \mathrm{dpl}$. Menurut Kusmana dan Susanti (2015), hutan hujan tropika terbagi menjadi tiga zone; zona I, hutan hujan bawah dengan

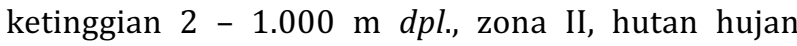
tengah dengan ketinggian 1.000-3.000 m dpl., dan zona III, hutan hujan atas dengan ketiggian di atas $3.000 \mathrm{~m} \mathrm{dpl}$.

Tabel 2. memperlihatkan jenis tumbuhan yang menguasai kawasan atau dominan pada berbagai kategori. 
Tabel 2. Jenis Tumbuhan Dominan pada setiap K'ategori di Kawasan Hutan Gunung Galunggung pada 2 (dua) Zona Ketinggian

\begin{tabular}{|c|c|c|c|c|c|}
\hline & Zona I & & & Zona II & \\
\hline Nama Daerah & Nama Jenis & $\begin{array}{l}\text { INP } \\
\text { (\%) }\end{array}$ & Nama Daerah & Nama Jenis & $\begin{array}{l}\text { INP } \\
\text { (\%) }\end{array}$ \\
\hline \multicolumn{6}{|l|}{ Pohon } \\
\hline Kurai & Trema orientalis & 83,09 & Kurai & Trema orientalis & 90,87 \\
\hline Kibenteur & & 47,91 & Dadap cangkring & & 49,73 \\
\hline Nangsi & Villebrunea rubescens & 39,18 & Hamerang & Vernonia arborea & 45,93 \\
\hline Kondang & & 36,65 & Beunying & Ficus fistulosa & 22,03 \\
\hline Hamerang & Vernonia arborea & 24,46 & Nangsi & Villebrunea sp. & 20,85 \\
\hline \multicolumn{6}{|l|}{ Tiang } \\
\hline Paku Bagedor & Cyathea contaminans & 47,36 & Paku Bagedor & Cyathea sp. & 78,33 \\
\hline Kaliandra & Calliandra calothyrus & 38,75 & Dadap cangkring & & 38,52 \\
\hline Nangsi & Villebrunea rubescens & 31,89 & Beunying & Ficus fistulosa & 23,61 \\
\hline Saninten & Castanopsis argentea & 21,24 & Nangsi & Villebrunea sp. & 19,08 \\
\hline \multicolumn{6}{|l|}{ Pancang } \\
\hline Kaliandra & Calliandra calothyrus & 71,36 & Nangsi & Villebrunea sp. & 43,36 \\
\hline Kiseureuh & Piper aduncum & 46,09 & Dawola & Moutsia sp. & 42,24 \\
\hline Pinus & Pinus merkusii & 24,31 & Kapirit & Nangsificus sp. & 37,46 \\
\hline Ki leho & Saurauia bracteosa & 23,61 & Kiseureuh & Piper aduncum & 36,73 \\
\hline \multicolumn{6}{|l|}{ Semai } \\
\hline Beunying & Ficus fistulosa & 39,20 & Nangsi & Villebrunea sp. & 44,67 \\
\hline Jambu monyet & Psidium sp. & 38,65 & Saliara & Lantana camara & 39,61 \\
\hline Kirinyuh & Euphatorium sp. & 26,17 & Paku sayur & Asplenium sp. & 31,68 \\
\hline
\end{tabular}

Keterangan : INP : Indeks Nilai Penting

Dari Tabel 2. terlihat bahwa jenis kurai (Trema orientalis) pada kategori pohon adalah jenis pohon yang paling menguasai di ke dua zona diikuti oleh Nangsi (Villebrunea rubescens) dan hamerang (Vernonia arborea). Perbedaan ketinggian tempat untuk ketiga jenis tersebut tidak berpengaruh terhadap penguasaan kawasan. Dapat disimpulkan bahwa ketiga jenis pohon tersebut adalah tumbuhan asli hutan Gunung Galunggung yang memiliki kemampuan beradaptasi dengan baik pasca erupsi 1982-1983. Menurut Backer \& Bakhuizen (1965), jenis tersebut merupakan tumbuhan yang menjadi ciri khas hutan hujan tropis pegunungan.

Pada kategori tiang, paku bagedor (Cyathea contaminans) adalah jenis yang paling menguasai di kedua zona diikuti oleh nangsi (Villebrunea rubescens). Pada zona I, kaliandra lebih mendominasi dibandingkan dengan nangsi dan saninten, hal ini di mungkinkan karena pada zona I dengan ketinggian di bawah $1.000 \mathrm{~m} \mathrm{dpl}$., pohon kaliandra ini segaja di tanam oleh pihak terkait dalam rangka mengoptimalkan kawasan yang ada. Terlihat juga pada zona II, di atas $1.000 \mathrm{~m} \mathrm{dpl.,} \mathrm{kawasan} \mathrm{sudah}$ mulai di dominasi oleh tumbuhan asli hutan pegunungan.

Pada kategori pancang, terlihat di zona II tumbuhan perintis mendominasi kawasan. Kaliandra dan pinus adalah pohon yang sengaja di tanam dan penyebarannya cukup mendominasi di zona I ini. Ada pun kiseureuh adalah tumbuhan indikator kawasan yang sedang mengalami suksesi. Menurut informasi masyarakat setempat, kaliandra dalam beberapa tahun ke belakang sudah ditebang untuk diambil kayunya dan saat penelitian dilakukan sedang terjadi pertumbuhan kembali. Inilah salah satu alasan kategori pancang untuk kaliandra cukup dominan. Berbeda kondisinya dengan zona II, ketinggian tempat menjadi alasan sehingga tidak dilakukan penanaman di kawasan tersebut, pepohonan tumbuh secara alami dan masyarakat sangat jarang yang mencapai kawasan. Tumbuhan asli hutan pegunungan di zona II pada kategori pancang; nangsi, dawola, dan lainnya sudah terlihat menguasai kawasan.

Pada kategori semai, di kedua zona sudah mulai di kuasai oleh tumbuhan asli pegunungan, walaupun jenisnya berbeda yaitu Beunying (Ficus fistulosa) di zona I dan Nangsi (Villebrunea sp.) di zona II. Dapat disimpulkan bahwa dimasa yang akan datang kondisi vegetasi di kawasan akan berangsur berubah ke vegetasi alaminya.

\subsection{Kaitan Antara Penggunaan Sumber Daya Hutan Oleh Masyarakat dan Struktur Vegetasi Masyarakat di sekitar G.Galunggung} merupakan masyarakat yang sebagian besar berpenghasilan masih relatif rendah, sehingga untuk memenuhi kebutuhan hidup masyarakat tergantung dari keberadaan sumber daya alam sekitarnya. Pemanfaatan sumber daya alam hutan telah dilakukan sebelum terjadi erupsi pada tahun 1982-1983 dan masih dilakukan sampai sekarang. Sebelum terjadi erupsi, pemanfaatan sumber daya hutan oleh masyarakat cukup besar, karena pengendalian dari pihak-pihak terkait kurang begitu kuat. Akan tetapi pasca erupsi dengan adanya polisi hutan, pihak perhutani, dan pengarahan dari aparat desa setempat pemanfaatan sumber daya hutan lebih terkendali. 
Kesadaran masyarakat akan manfaat hutan semakin terbangun.

\subsection{Perubahan Kondisi Alam Secara Umum}

Hasil wawancara dengan beberapa Key informant menuturkan bahwa campur tangan manusia terhadap hutan G.Galunggung pasca erupsi tidak begitu besar, dibandingkan sebelum erupsi. Campur tangan yang terjadi pasca erupsi lebih kepada pemanfaatan sumber daya hutan terutama tumbuhan untuk dijadikan kayu bakar. Akan tetapi yang terjadi intensitasnya rendah dan penggunaan kayunya untuk kayu bakar sebagian besar mengambil kayu dari pohon kaliandra. Pihak perum perhutani dan aparat desa setempat memegang peranan penting dalam pengandalian ini. Sehingga dapat dikatakan bahwa perubahan kondisi vegetasi kawasan hutan G.Galunggung relatif tidak terganggu oleh interaksi masyarakat.

\section{Kesimpulan}

- Berdasarkan sebaran plot kuadrat yang diletakkan secara random, di kawasan ini di temukan sebanyak 43 jenis tumbuhan, yang terbagi ke dalam kategori pohon dewasa, tiang, pancang, dan semai. Dari ke 43 jenis tersebut, kategori pohon sebanyak 12 jenis, kategori tiang sebanyak 25 jenis, kategori pancang sebanyak 23 jenis, dan kategori semai sebanyak 21 jenis.

- Jenis yang menguasai pada setiap kategori vegetasi adalah kurai (Trema orientalis) pada kategori pohon, paku bagedor (Cyathea contaminans) pada kategori tiang, kiseureuh (Piper aduncum) pada kategori pancang, dan nangsi (Villebrunea rubescens). pada tingkat semai.

- Komposisi jenis vegetasi yang terdapat pada dua zona yang berbeda menujukkan adanya perbedaan, tetapi dapat dikatakan bahwa jenisjenis tumbuhan yang dominan pada dua zona tersebut hampir sama.

- Hutan Gunung Galunggung masih berada dalam kondisi yang belum klimaks, populasi dan strukturnya masih dalam tahap perkembangan/ tahap sekunder. Ditandai dengan tingkat keanekaragamannya yang sedang dan ditemukannya jenis huru (Litsea sp.), puspa (Schima walichii), Hamerang (Vernonia arborea), dan nangsi (Villebrunea rubescens), serta jenis lainnya yang merupakan cirri karakteristik hutan hujan pegunungan yang berada pada tahap suksesi "seral".

\section{Ucapan Terimakasih}

Penulis mengucapkan terimaksih kepada Dikti dan DRPMI Unpad melalui penelitian Hibah Doktor dengan no. Kontrak 431/UN6.3.1/PL/2016.

\section{DAFTAR PUSTAKA}

Andi Kusumo, Azis Nur Bambang, Munifatul Izzati. 2016. Struktur Vegetasi Kawasan Hutan Alam dan Hutan Rerdegradasi di Taman Nasional Tesso Nilo. Jurnal Ilmu Lingkungan, 14(1): 19-26

Backer, A. \& Bakhuizen Van Den Brink, R.C. Jr. 1965. Flora of Java. Vol. II Angiospermae. The Netherlands: N.V.P. Noordhoff - Groningen.

Bismark, M. 2011. Prosedur Operasional Standar (SOP) untuk survei keragaman jenis pada kawasan konservasi. Pusat Penelitian dan Pengembangan Kehutanan. Kementerian Kehutanan dan International Tropical Timber Organization. Bogor.

Daryono, H. 2009. "Potensi, Permasalahan Dan Kebijakan Yang Diperlukan Dalam Pengelolaan Hutan Dan Lahan Rawa Gambut Secara Lestari." Analisis Kebijakan Kehutanan 6 (1981): 71-101.

Departemen Kehutanan, 2007, Statistik Kehutanan Indonesia, Biro Perencanaan Departemen Kehutanan Indonesia.

Fachrul, M. 2012. Metode sampling bioekologi. Bumi Aksara. Jakarta.

Indriyanto. 2006. Ekologi Hutan. PT Bumi Aksara. Jakarta.

Kusmana C. dan Susi Susanti. 2015. Komposisi dan struktur tegakan hutan alam di hutan pendidikan Gunung Walat, Sukabumi. Jurnal Silvikultur Tropika, 5(3): 210-217

Leksono, A. 2007. Ekologi pendekatan deskriptif dan kuantitatif. Bayumedia Publishing. Malang.

Odum, E.P., 1971. Fundamentals of Ecology. W. B. Saunders Company, Phyladelpia, London, Toronto.

Purba, C. P., Nanggara, S. ., Ratriyono, M., Apriani, I., Rosalina, L., Sari, N. ., \& Meridian, A. . 2014. Potret keadaan hutan indonesia 2009 - 2013. Forest Watch Indonesia. Bogor.

Purbowaseso, B. 2004. Pengendalian Kebakaran Hutan. PT. Rineka Cipta. Jakarta.

Purwaningsih, P. 2005. Species composition and vegetation structure in Pakuli area, Lore Lindu National Park, Central Sulawesi. Biodiversitas, Journal of Biological Diversity, 6(2), 123-128

Soerianegara, I. 1978. Ekologi Hutan Indonesia. Bogor: Institut Pertanian Bogor.

Tjitrosoepomo, G. 2007. Taksonomi tumbuhan spermatophyta. Gajah Mada University Press. Yogyakarta

Van Steenis, C. G. G., Bloembergen, S., \& Eyma, P. 1975. Flora untuk sekolah di Indonesia. PT. Pradnya paramita. Jakarta.

Widayat, D., H. Djuned, K.J. Gurmaya, R. Partasasmita. 2007. Master Plan Pengembangan Agribisnis Sayuran di Kawasan sariwangi, Kabupaten Tasikmalaya. Lembaga Penelitian Unpad.

Yulianto, K. 2014. Panduan lapangan pengenalan 101 jenis pohon hutan hujan dataran rendah. WWF Riau. Pekanbaru. 